\title{
Transcatheter management of post infarction ventricular septal repture with concomitant coronary angioplasty
}

\section{Introduction}

Ventricular septal defect (VSD) or rupture (VSR) after acute myocardial infarction is an uncommon but catastrophic event with poor prognosis. ${ }^{1-5}$ Although immediate surgical closure with hemodynamic support (IABP) is the treatment of choice as adviced by the American College of Cardiology and American Heart Association (ACC/ $\mathrm{AHAr}^{-9}$ ). Advanced patient age, hemodynamic instability, surgical challenges and comorbidities still associated with high mortality rates $^{\prime 2}{ }^{\prime 1^{\circ}}$. Medical therapy alone has no role in improving survival and associated with very poor prognosis ${ }^{01}{ }^{\prime}$. Partial or complete closure of VSR through transcatheter approach appears to be very attractive alternative to surgery and associated with much less mortality and morbidity especially in good centers $\mathrm{m}^{2-15} \mathrm{We}$ introduce a case of large VSR that closed with PIMVSD concomitantly with coronary angioplasty of critically stenosed mid left anterior descending coronary artery it is the first case in Iraq with critical coronary artery disease and large post myocardial infarction VSR which was managed through transcatheter approach and the patient survived after closure.

\section{Case report}

A 68 years old female patient who is a known case of hypertension and dyslipidemia presented to the emergency department with typical ischemic chest pain and electrocardiographic findings of anteroseptal STEMI. Patient received thrombolytic therapy and consequently had coronary angiography and then refered to our hospital, 15days post infarction for further management. Transthoracic echocardiography revealed moderate left ventricular dysfunction, EF 40\%, anteroseptal and apical akinesia, small apical aneurysm, large VSR (17'14mm) with dominant left to right shunt and right ventricular systolic pressure of $45 \mathrm{mmHg}$. An informed consent was obtained and the patient prepared for elective cardiac catheterization with intending of transcatheter closure of the VSR. Under local anesthesia and transthoracic echocardiographic guidance, right femoral and internal jugular vascular access was obtained and selective left coronary artery and left ventricle (LAO/Cranial 35/35) angiography was performed (Figure 1).

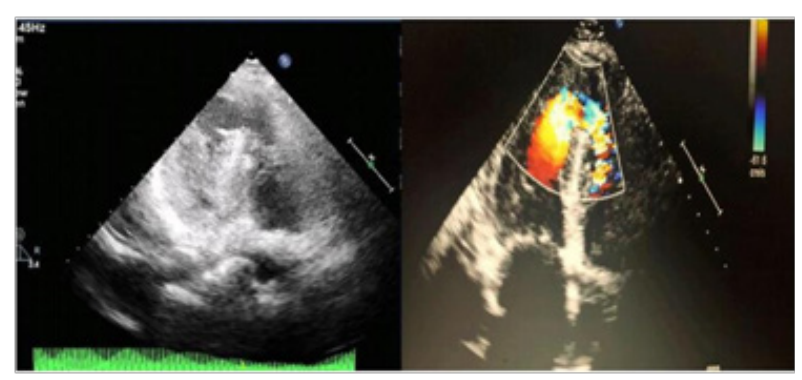

Figure I Transthoracic echocardiographic four chambers view shows the apical ventricular septa! defect with left to right shunt.
Volume II Issue 3 - 2018

\author{
Khalid Amber \\ Director of Cath Lab and Najaf Cardiac Center, Iraq
}

Correspondence: Khalid Amber, Director of Cath Lab and Najaf Cardiac Center, Iraq, Email khalidamber4@gmail.com

Received: June II, 2018 | Published: June II, 2018

Angioplasty of the mid LAD was achieved successfully with $14^{\prime} 2 \mathrm{~mm}$......stent. the VSR was crossed from the LV with a $6 \mathrm{~F}$ cut pigtail and standard terumo wire 0.35 inch where it advanced into the pulmonary artery. A manually modified $6 \mathrm{~F}$ multipurpose catheter was introduce through the internal jugular vein into the pulmonary artery where the terumo wire had been snared and exteriorized. A 20mm PIMVSD device (AGA medical) was advanced into the left ventricle and under transthoracic echocardiographic and continuous hand-injection through the already cutted pigtail into the left ventricle, the Figure 2 \& Fogure 3.

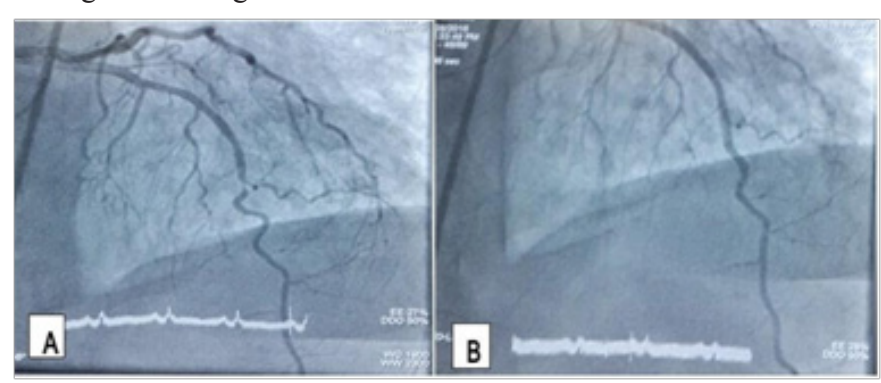

Figure 2 critical mid left anterior descending artery stenosis (A) that successfully managed with xience stent 2" $14 \mathrm{~mm}$ (B).

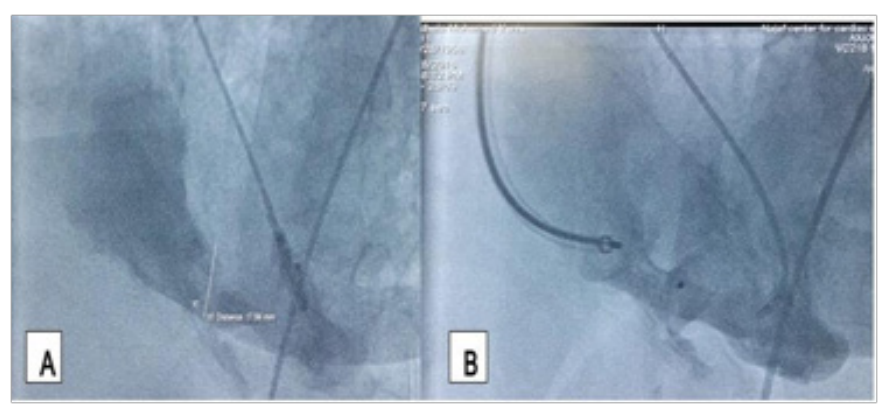

Figure 3 Left ventricular angiography (LAO/Cranial 35/35) before (A) and after (B) transcatheter closure of ventricular septa! repture with $20 \mathrm{~mm}$ |3| MVSD device, small residual shunt was detected. 


\section{Discussion}

Although surgical management of the VSR with concurrent coronary artery bypass grafting is the treatment of choice for post infarction VSR, still significant percentage of patients had high mortality rate and specially those with hemodynamic instability, revealed moderate left ventricular dysfunction, EF $40 \%$, anteroseptal and apical akinesia, small apical aneurysm, large VSR (17”14mm) with dominant left to right shunt and right ventricular systolic pressure of $45 \mathrm{mmHg}$. An informed consent was obtained and the patient prepared for elective cardiac catheterization with intending of transcatheter closure of the VSR. Under local anesthesia and transthoracic echocardiographic guidance, right femoral and internal jugular vascular access was obtained and selective left coronary artery and left ventricle (LAO/Cranial 35/35) angiography was performed.

Angioplasty of the mid LAD was achieved successfully with 14 " $2 \mathrm{~mm}$......stent. the VSR was crossed from the LV with a $6 \mathrm{~F}$ cut pigtail and standard terumo wire 0.35 inch where it advanced into the pulmonary artery. A manually modified $6 \mathrm{~F}$ multipurpose catheter was introduce through the internal jugular vein into the pulmonary artery where the terumo wire had been snared and exteriorized. A 20mm PIMVSD device (AGA medical) was advanced into the left ventricle and under transthoracic echocardiographic and continuous hand-injection through the already cutted pigtail into the left ventricle, the device deployed completely. At that time, a significant rise in the left ventricle systolic pressure was obsereved. Only after device stability was assessed by left ventricle angiography and transthoracic echocardiography, the device was released. The patient transferred to the intensive care unit and discharged three days later with a well general condition.

Although surgical management of the VSR with concurrent coronary artery bypass grafting is the treatment of choice for post infarction VSR, still significant percentage of patients had high mortality rate and specially those with hemodynamic instability, cardiogenic shock, and/or comorbidities. Generally, closure of the ventricular septa! repture was either performed early after the acute myocardial infarction (less than 14days) which usually carry a high rate of mortality or late (more than 14days) which was associated with successful closure of more than $70 \%$. Transcatheter closure with different types of devices increasingly achieved as good alternative for surgical closure with high rate of closure and much less rate of early mortality. The aim of transcatheter closure may be only a bridge to an urgent surgery or as definitive primary treatment with complete closure. Our case is the first case of post MI VSR in Iraq that was managed by transcatheter approach with concomitant coronary angioplasty and VSR closure at the same session and with successful results. Small hemodynamically non significant residual shunt was detected on transthoracic echocardiography at 24hours follow up. The procedure passed smoothly without significant complications which may be related to the good preparations and the unique team that involved coronary/structural and congenital interventionalists.

\section{Acknowledgements}

None.

\section{Conflitc of interest}

The author declares no conflict of interest.

\section{References}

1. Crenshaw BS, Granger CB, Birnbaum Y, et al. Risk factors, angiographic patterns and outcomes in patients with ventricular septal defect complicating acute myocardial infarction. Gusto-I global utilisation of steptokinase and TPA for occluded coronary arteries. Trial Investigators. Circulation. 2000;101(1):27-32.

2. Deja MA, Szostek J, Widenka K, et al. Post infarction ventricular septa! Defect-can we do better? Eur J Cardiothorac Surg. 2000;18(2):194-201.

3. Mantovani V, Mariscalco G, Leva C, et al. Surgical repair of post-infarction ventricular septa! defect: 19 years of experience. International Journal of Cardiology. 2006;108(2):202-206.

4. Labrousse L, Choukroun E, Chevalier JM, et al. Surgery for post-infarction ventricular septa! defect (VSD): risk factors for hospital death and long term results. Euro J Cardiothor Surg. 2002;21(4):725-732.

5. Jeppsson A, Liden H, Johnsson P, et al. Surgical repair of post infarction ventricular septa! defects: a national experience. Euro J Cardiothor Surg. 2005;27(2):216-221.

6. Ryan TJ, Antman EM, Brooks NH, et al. ACC/AHA guidelines for the management of patients with acute myocardial infarction. A report of the American college of cardiology/american heart association task force on practice guidelines (committee on management of acute myocardial infarction). $\mathrm{J} \mathrm{Am} \mathrm{Coll} \mathrm{Cardiol}$. 1999; 28(5):1328-1428.

7. Antman EM, Anbe DT, Armstrong PW, et al. ACC/AHA guidelines for the management of patients with ST-elevation myocardial infarction - executive summary. Circulation. 2004;110(5):588-636.

8. Thiele H, Lauer B, Hambrecht R, et al. Short- and longterm hemodynamic effects of intra-aortic balloon support in ventricular septa! defect complicating acute myocardial infarction. Am J Cardiol. 2003;92(4):450-454.

9. Maltais S, Ibrahim R, Basmadjian AJ, et al. Postinfarction ventricular septa! defects: towards a new treatment algorithm? Ann Thorac Surg. 2009;87(3):687-692.

10. Menon V, Webb JG, Hillis LD, et al. Outcome and profile of ventricular septa! rupture with cardiogenic shock after myocardial infarction: a report from the SHOCK trial registry. Should we emergently revascularize occluded coronaries in cardiogenic shock? J Am Coll Cardiol. 2000;36(3 Suppl A):1110-1116.

11. Thiele H, Kaulfersch C, Daehnert I, et al. Immediate primary transcatheter closure of postinfarction ventricular septa! defects. Eur Heart J. 2009;30(1):81-88.

12. Calvert PA, Cockburn J, Wynne D, et al. Percutaneous closure of postinfarction ventricular septa! defect: in-hospital outcomes and long-term follow-up of UK experience. Circulation. 2014;129(3):2395-2402.

13. Marinakis A, Vydt T, Dens J, et al. Percutaneous transcatheter ventricular septa! defect closure in adults with Amplatzer septa! occluders. Acta Cardiol. 2007;62(4):391-395. 
14. Jacek B, Malgorzata S, Jacek K, et al. Transcatheter closure of postinfarction ventricular defects using Amplatzer devices. Rev Esp Cardiol. 2007;60(5):548-551.
15. Ahmed J, Ruygrok PN, Wilson NJ, et al. Percutaneous closure of post-myocardial infarction ventricular septal defects: a single centre experience. Heart Lung Circ. 2008;17(2):119-123. 